\title{
Evolution of the Campaign in the Philippine Islands.
}

H. W. WADE.

WE plan of the anti-leprosy campaign in the Philippine Islands has undergone decided change in the past - few years. It has long been unusually extensive, though essentially simple. As now planned, and to some extent as it is actually in operation, it is more elaborate and differs more or less from that carried on in any other comparable region.

Systematic anti-leprosy work in the Philippines was started early in the present century. During Spanish times the only work on behalf of lepers was done by the Catholic Church, which maintained three small institutions, by nature simply refuges for those who chose to go to them. Those that were established at Manila (the San Lazaro Hospital) and Cebu have continued in use; they are the largest detention stations in the Islands, and the only places outside of Culion where as yet, under the present system a large number of lepers are being kept for any length of time.

Very early in the American regime preparations were begun for systematic work by the Government. At that time general (i.e., compulsory) segregation of all known lepers who were considered infectious (because bacteriologically positive by the usual methods of examination) was the only available measure that gave any promise of success under existing conditions. It is to be realised that the general, economic and personal hygienic level of the masses was not high, and that home isolation was utterly impracticable, as it still is. It was concluded that all lepers should be isolated in a single colony. 
After due investigation Culion was chosen for the projected colony. This island, one of the Calamianes group just north of Palawan, in the westernmost and one of the most isolated and least developed groups of the archipelago, was acquired at little expense. In several ways it was admirably adapted to development for the purpose. Preparatory work was started in 1901, but it was not until 1906 that enough had been done to permit taking the first shipload of lepers there. Within a very few years all that were known to the health officials were transported.

It was very unfortunate for the campaign that Culion acquired a bad reputation among the people. The segregation measure itself was naturally unpopular among those whom it was intended to benefit most, for the friends of lepers objected to giving them up, at least so long as they were not repulsive. Under the best of conditions the facts that the colony was essentially a collecting place of hopeless, afflicted people waiting to die, and was practically inaccessible to the friends of the inmates, would have created a repugnance for it. Actually the colony was for some years not well developed, and worst of all, the death rate was at first very high. Many of the patients were in bad condition because of previous neglect. The diet was faulty; not only was the fresh vegetable element insufficient, market gardening by the inmates was not adequately developed until much later, but the effect of feeding white (" over-milled ") rice was not realised in those days, and beri-beri took heavy toll. Consequently there arose an actual horror of Culion that, though now greatly modified, has not entirely subsided in spite of the comparatively ideal conditions now existing and the generally hopeful spirit of the inmates.

When all the known lepers had been transferred to Culion it was expected that the incidence of leprosy would decline rapidly thereafter, an expectation which did not materialise. This was largely owing to the fact that the health officials failed to realise that there would be remaining a large number of hidden or undetected lepers as a result of such measures. One cannot state what the conditions would have been had not this work been commenced, but it is known that in a period of fifteen years the average number of cases segregated annually did not decline materially. On the other hand, it is not possible to surmise the result of such a system had it been carried on for a longer period without modification.

A new era commenced in 1921 when, after preliminary small-scale trials, the new treatment work was systematically 
started at Culion. By the middle of 1922 it was being given to all of the more than 5,000 inmates who could take it. The Culion staff was increased until it now comprises 19 medical men (including two administrative officers and three on the pathological staff), together with three chemists, 23 nurses and various other workers. Concerning the routine and research work done at Culion and elsewhere, suffice it to say that the results obtained have had an important influence on the general campaign in the Philippines, and have made it possible to raise in the United States a special fund, the Leonard Wood Memorial for the Eradication of Leprosy, to aid in the intensification of research.

It is perhaps difficult for any who have not experienced it themselves to realise just how great is the difference that the advent of a comparatively successful treatment has made in the whole situation. Once the superior effectiveness of the new treatment was determined it became possible to modify the campaign plan and to reinforce the compulsory segregation efforts by positive attraction. It also became possible to extend the work to deal with the "incipient" cases (more accurately, those found clinically positive but bacteriologically negative), which are not subject to segregation under the law and for which, previously, nothing could be done.

When it began to be realised by the public that patients were really being cured (or, if it be preferred, " apparently cured ") and were being released in numbers the attitude toward the work began to undergo radical change. For the first time, lepers began to present themselves voluntarily. Several hundreds now come in each year. This very essential condition had previously been quite impossible of attainment. It has not been reached in all parts of the archipelago; most of the volunteers are from the Manila and Cebu regions, but these are the ones from which the largest number of lepers come, and to which, naturally, the largest number of ex lepers have returned. With time this influence will spread.

The first important change in the campaign programme was the decision to establish, when funds could be obtained, a "regional treatment station" in each of the five or six main geographical subdivisions of the archipelago. These institutions must of necessity be built on limited areas, and be of the asylum rather than the colony type ; most of the people will live in dormitories, and the sexes will be separated. According to the plan all lepers segregated will so far as possible be kept in these stations until their response 
to treatment can be determined. Those who improve satisfactorily, and who can be released in a reasonable time (two or at most three years), should never see Culion ; the others sooner or later will be sent there. In this well developed and well managed colony town, with its nearby farming areas and its extensive back-country and fishing grounds, most of the inmates do well, and their lives are remarkably free and normal, far more so than would be possible in a small leprosarium.

In part the treatment station system is intended to meet the objection of lepers to being removed from their home regions to the distant and maligned Culion colony. Other features that justify the system, are, firstly, the advantage of having those who are receiving intensive treatment under closer observation than is possible in a large colony, Secondly, the better morale that naturally exists where there are comparatively few disheartening, hopeless cases. Finally, regional stations will accelerate the infiltration of knowledge among the people of the neighbourhood around them. They will also create a hopeful and helpful attitude, and will serve as the centres for field work.

As yet this system is far from well established. The leper department of San Lazaro hospital in Manila and the old detention camp at Cebu, though both far from satisfactory, have been improved somewhat and selected patients are kept there as long as possible. A considerable number have already been released. No typical regional station as planned is as yet in operation, but the first, of 750-inmate capacity, is now being built at Cebu by The Leonard Wood Memorial, and will be occupied early in 1930 . There is hope that a second one, somewhat larger, will be built near Manila in the near future. Elsewhere, however, only comparatively small institutions, more in the nature of improved detention stations, will for the present be provided. Such a development is actually under way in Iloilo, Legaspi and Zamboanga. These minor stations, imperfect and inadequate though they be, will undoubtedly become as helpful in improving the attitude of the people of these regions as the present centres at Manila and Cebu.

The second new phase of the campaign that the treatment has made possible, spoken of inclusively as field work, has most important potentialities. In part the realisation of these depends upon earnest search by the rank and file of the health personnel for " incipient " cases, and effective treatment of these in municipal clinics. Unfortunately, the immediate possibilities of this scheme seem limited. 
Because of several conditions, one of them the multifarious other activities required of the health officers, most of whom work on a part-time basis, special workers are needed to cover each field, at least to get the work properly under way. This is being done in the Cebu area where a special skin clinic has been in operation for nearly two years, and a specially equipped travelling clinic will soon be in operation. Special skin clinics have recently been started in some of the other regions.

The results that are obtained at Cebu are very encouraging as to the possibilities of dispensary treatment for the comparatively easily cured incipient cases. Many, though by no means all, of the patients have taken treatment fairly regularly and to good effect, and meanwhile, they have continued their normal lives with, on the whole, fortunately little stigmatisation. This work, and the extension of it in the field through travelling clinics and other means, can, if properly conducted, be made to accelerate greatly the education of the people, otherwise a difficult matter in a population the masses of which read little, seldom see the moving picture, and do not have the radio. For a time this activity will to some extent be reinforced by field workers which the Philippine Anti-Leprosy Society is providing, primarily to survey the condition of ex-lepers. Many of these (about $2,000)$ have been released in recent years. Because they are not well received in their communities, they create a local new sociological and humanitarian problem. Effective as this field work might be if it were possible to carry it out on a sufficiently extensive and intensive scale, the inherent difficulties unfortunately put it, for the present at least, in the category of an important adjunct rather than a prime measure.

The Philippine system as projected, then, combines segregation of the infective cases, attraction of such cases by the treatment and to some extent by local rather than distant segregation, dispensary treatment of the incipient cases, and intensive survey and educational work in the field. Though it is realised that to extend this whole system immediately over the entire archipelago is quite impossible, the authorities believe that by doing so as rapidly as possible, or if necessary, doing the more intensive, detailed work region by region, there is much more hope than ever before of seeing leprosy eradicated, or at least reduced to comparatively unimportant proportions. The advantages of this system over any other simpler one will not be discussed here. 